\title{
Blending virtual reality with traditional approaches to encourage engagement with core chemistry concepts relevant to an undergraduate pharmacy curriculum
}

\author{
James Pearce Hall ${ }^{*}$ iD; Sarah Ann Allman ${ }^{1,2^{*}}$ (iD). \\ ${ }^{1}$ Reading School of Pharmacy, University of Reading, United Kingdom ～ 2 Leicester School of Pharmacy, De Montfort University, United Kingdom
}

\author{
Keywords \\ Drug Design \\ Molecular Models \\ Molecular Structure \\ Virtual Reality \\ Correspondence \\ Dr James Hall \\ Room 219 \\ Chemistry and Pharmacy Building \\ Whiteknights Campus \\ University of Reading \\ Reading \\ RG6 6DX \\ United Kingdom \\ James.Hall@reading.ac.uk
}

*Both authors contributed equally to this work

\begin{abstract}
Students studying pharmacy often lack motivation to engage with chemical principles. In particular, they often find fundamental chemical concepts such as the visualisation of three-dimensional structures challenging. This programme description reports the design and implementation of a teaching session where stand-alone virtual reality (VR) technology was offered alongside traditional methods of instruction in an attempt to encourage students to engage with fundamental chemistry concepts relating to the three-dimensional structures of drug molecules. By using VR technology in combination with paper-based in-class exercises and supporting material delivered via a virtual learning environment, the authors demonstrate that virtual reality could be used to both reinforce learning and enhance engagement with a topic which students often find challenging. $A$ blended approach employing different methods of delivery presents the advantage that it allows the user control over the level of interaction with each individual element. As such, VR becomes a valuable instructional tool rather then the focus of the session or a distraction. To evaluate the sessions, student feedback was collected using a 'ballot-box' system where students could provide anonymous free response comments. Feedback from the session was overwhelmingly positive and it was noted that the optional use of VR technology kept students engaged in tackling paper-based exercises in an area of curriculum which learners often find difficult. It is noted that a blended approach can help to overcome several of the barriers in the use of VR in a classroom setting. In addition, it highlights that effective deployment of such technology is both viable and beneficial on a classroom scale. In the future, the authors hope to apply these methods to other parts of the curriculum
\end{abstract}

\section{Introduction}

For students studying pharmacy, chemistry is an integral part of the curriculum. The General Pharmaceutical Council indicative syllabus for pharmacy specifies that students must be able to understand and apply chemistry concepts such as those relating to chemical structure, bonding and nomenclature, functional groups and reactivity and, the synthesis of therapeutic molecules (General Pharmaceutical Council, 2011). Core chemistry concepts are also essential for a deep understanding of the bioscience components of pharmacy undergraduate programmes from the molecular level to the organism level (Ang \& van Reyk, 2013). In addition, they are important to enable students to perform functions necessary to deliver care (Alsharif, Destache, \& Roche, 1999). Examples of the latter include an understanding of drug interactions and side effects which have implications for patient safety (Fergus \& Kostrzewski, 2011) and 
supported decision making in a healthcare environment (Faruk Khan, Deimling, \& Philip, 2011). Studies in pharmacy and allied health professions such as nursing (Craft et al., 2017) have suggested that student engagement with core science principles is influenced by factors such as anxiety and perceptions of the relevance of science to practice. Studies of nursing students (Smith et al., 2018) suggest that students often lack confidence rather than ability when faced with chemical concepts, with similar issues being highlighted in the context of teaching other foundational sciences (Friedel \& Treagust, 2005) where the subject is perceived as difficult (Gordon \& Hughes, 2013; Ralph et al., 2017). Anxiety surrounding chemistry as a non-focus subject has also been documented by science educators, particularly in students studying for qualifications in allied health professions (Widanski \& McCarthy, 2009). This has been linked in part to preparedness in courses such as nursing (where science may not be a prerequisite for admission), but also in courses such as pharmacy (where chemistry is a prerequisite). In the latter case, this has been attributed to time elapsing between the study of relevant chemical concepts at secondary level and the later application of these concepts at university level (Trippier, 2018).

Much emphasis is given to presenting chemistry in the context of health and practice in order to promote engagement with chemical principles and encourage effective learning. In the United Kingdom (UK) pharmacy curriculum, the communication of the relevance of organic chemistry is often achieved by the selection of therapeutic molecules as examples. Studies have shown that pharmacy students have no issue recognising the relevance of organic chemistry to their discipline (Prescott, Wilson, \& Wan, 2014; Wehle \& Decker, 2016). Similarly in nursing, studies have shown that nursing students also appreciate the scientific content of courses (Clifton \& McKillup, 2016) but that some concepts are viewed as more relevant than others (Brown et al., 2012). The relevance of some fundamental chemical concepts to the practice environment may therefore present a challenge to communicate. Contextualisation does, therefore, remain important in reinforcing relevance and in assisting students in translating scientific knowledge to practice.

Both positive and negative factors influencing student emotion (such as enjoyment or anxiety related to assessment) have been shown to be related to academic performance in organic chemistry (Gibbons et al., 2018). Willingness of students to engage has also been shown to be compounded by factors such as the positive attitudes and enthusiasm of teaching staff (Vahdat, 2009; Alsharif \&
Qi, 2014). Many studies have presented approaches to teaching chemistry where different pedagogic methods are employed to support traditional lectures, enhance the learning experience, and increase student performance in science subjects (Freeman et al., 2014). These have included student-centred pedagogic approaches, such as the use of clinical scenarios (Mahaffey, 2019b) or problem-based or collaborative learning exercises (Stewart et al., 2011; Chase, Pakhira, \& Stains, 2013) and the use of physical models (Hall et al., 2017). A variety of technology-enhanced learning approaches have also been examined, from using media resources in combination with traditional lectures (Gloudeman et al., 2018; Rose, 2018) to computational modelling classes (Carvalho, Borges, \& Bernardes, 2005; Mahaffey, 2019a). The ability to deliver sessions of these types can be constrained by logistical issues such as the availability of appropriate specialist teaching facilities such as computer rooms or resources such as hardware (Trippier, 2018).
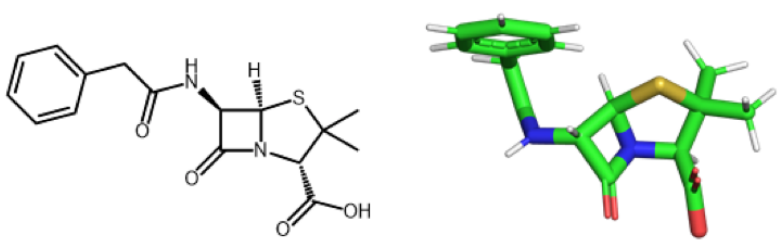

Figure A: An isomer of penicillin drawn in skeletal format (left) and as a 3D representation (right). Atoms are coloured according to type, with carbon in green, nitrogen in blue, oxygen in red, hydrogen in white and sulphur in yellow.

The success of these approaches has been linked to activities changing student perception of fundamental science concepts, or reinforcing the relevance of such concepts to practice. However, active learning approaches which engage students in the learning process (Prince, 2004) can also act as a means to stimulate student enthusiasm and enjoyment in science subjects (Armbruster et al., 2009). For example, chemical concepts relating to molecular shape and structure are of key importance to understanding the chemical and biochemical concepts relevant to pharmacy but students often find them challenging (Dries et al., 2017). This in part is due to the requirement for translation between symbolic representations of structures presented in two dimensions (2D) and three-dimensional (3D) shape (Cooper \& Oliver-Hoyo, 2017) (Figure A). Showing 3D structures in immersive environments rather than in $2 \mathrm{D}$ 
environments (as an animation on a computer screen) has been previously demonstrated to enhance both understanding and motivation for learning core chemistry concepts such as these (Limniou, Roberts, \& Papadopoulos, 2008). Combined, these approaches serve to encourage the deep engagement with concepts necessary for the confident engagement with science concepts required to support the practice environment.

\section{The use of virtual reality in health education}

The primary objective of VR technologies is to allow a user to operate within an artificially created environment (Latta \& Oberg, 1994). Although there are many different types of experiences which can be classified as VR, fully immersive VR often employs head mounted displays to allow the user to interact with the artificial environment (Figure B). In head-mounted displays, the simultaneous projection of separate images to each eye from different perspective creates the sensation of a $3 D$ environment. Displays can vary greatly in terms of technological capability, with features such as motion interfaces and haptic feedback elements employed in high-end devices to further enhance the level of user immersion and interaction. VR technology has found extensive use in recreational pursuits, healthcare settings (Garcia-Palacios, et al., 2002; Keefe et al., 2012; Özer \& Yöntem, 2019; Johnson et al., 2020), business (Flavián, Ibáñez-Sánchez, \& Orús, 2019) and in education and training. In the latter case it has been used for such purposes as simulation and exploratory learning (Logishetty, Rudran, \& Cobb, 2019). Immersive technologies support a constructivist modality of learning, in that they provide a means to allow students to explore and interact with the environment and construct knowledge from their experiences (Hedberg \& Alexander, 1994).

In health education, VR has been used for the simulation of practical experiences in a safe and controlled environment (Lewis et al., 2011; Smith \& Hamilton, 2015). It has also been used to introduce spaces to students where access would be otherwise restricted (Davies, Crohn, \& Treadgold, 2019). A variety of applications have also been developed with relevance to the education of health professionals. These include applications designed to facilitate the visualisation of fundamental science concepts (Sharecare, 2017) and those communicating first-order experiences such as patient experiences of conditions such as neurodegeneration or sensory impairment (Galactig, 2019). Studies in pharmacy education have shown that VR technology can be used to facilitate team-based pedagogic approaches between students working remotely (Coyne et al., 2018).

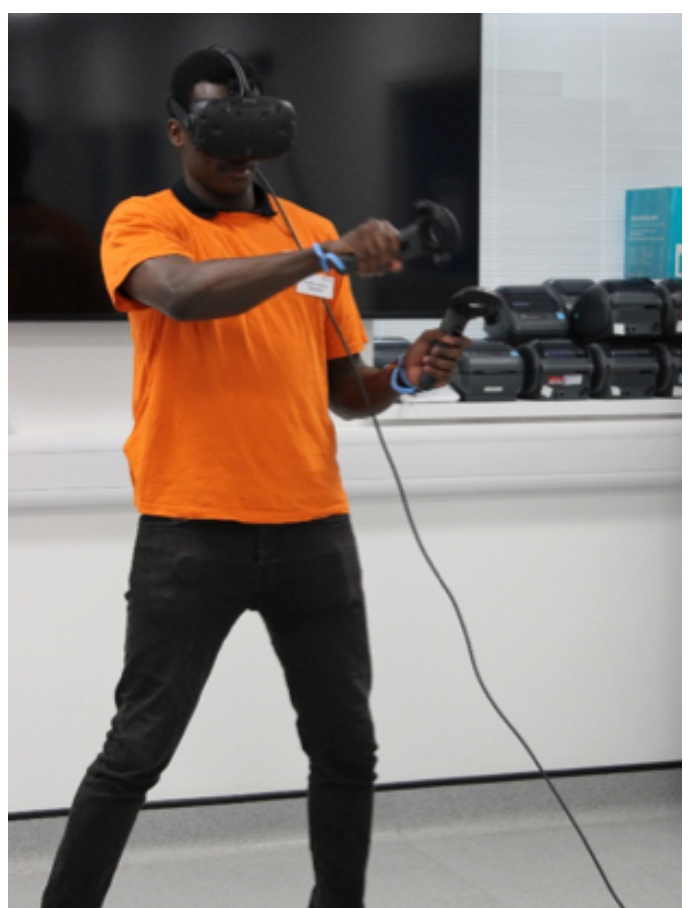

Figure B: An M.Pharm. student (University of Reading, UK) using a head mounted VR display (HTC Vive)

\section{Barriers to adopting virtual reality technology}

There are a number of potential barriers for the adoption of VR technologies in the classroom. These include cost of hardware, instructor confidence in working with new or unfamiliar technology, and health and safety considerations.

VR technology varies greatly in terms of cost. Low-cost stand-alone VR setups such as Google Cardboard take advantage of a user's mobile phone, which is then placed into a cardboard enclosure fitted with lenses. Devices such as these can be used for viewing videos and other (typically) non-interactive content (Brown \& Green, 2016). At an intermediate cost level, stand-alone devices such as the Oculus Go offer both 'limited interactivity (in comparison to high-end, high-cost devices) and a higher quality experience than using a mobile phone. Both low and intermediate-level devices typically offer 3DOF (degrees of freedom) tracking; meaning that they can track a user rotating their view in an $\mathrm{x}, \mathrm{y}$ and $\mathrm{z}$ direction. The design of such headsets ensures that the experience is significantly more immersive than low-cost VR solutions. Current highest-end consumer VR solutions (such as the HTC Vive Pro, Oculus Rift and Oculus Quest, amongst others) offer 6DOF tracking, which means a user can move freely within a virtual space and is not limited to simply rotating their head within a fixed viewpoint. Higher-end VR systems with enhanced levels of functionality rarely 
function as stand-alone devices, often requiring external computer hardware to drive the VR environment (which introduces additional cost implications). This has the potential to present problems for institutions and departments in terms of the financial outlay required to implement such methods on a class scale. Recent studies have, however, shown that stand-alone VR systems provide acceptable levels of immersion when compared to more interactive VR platforms (Amin et al., 2016; Papachristos, Vrellis, \& Mikropoulos, 2017). In addition, cost implications for the user cannot be overlooked if students are required to download content onto personal devices such as smartphones (Davies et al., 2019).

The reticence of instructors to adopt emergent technology has been cited as a barrier to the use of VR in an educational setting (Alfalah, 2018). Similar reticence amongst instructors has been noted for other types of technology and also for other active learning techniques (Shadle, Marker, \& Earl, 2017). Requiring that students use their own devices has been shown to present additional problems for the instructor, relating to the input of support needed to manage differences in levels of digital fluency within the student cohort (Davies et al., 2019).

There are health and safety considerations cited around the use of VR technology. Manufacturers of hardware do not recommend persons with certain pre-existing health conditions work with VR. These can include persons with heart conditions, psychiatric disorders or binocular vision abnormalities (Oculus, 2019). Motion sickness and nausea (often termed 'cyber sickness') have also been associated with immersive environments (Sharples et al., 2008; Rebenitsch \& Owen, 2016). This has the potential to exclude some learners from the learning environment.

\section{Description of innovation}

Within the School of Pharmacy at the University of Reading (UK), molecular structure and shape are key chemical concepts which are taught as part of the 1st year M.Pharm. curriculum. An understanding of the 3D shape and structure of molecules provides the foundation for later elements of the curriculum, including the study of drug synthesis, drug-receptor interactions, and the physico-chemical properties of therapeutics. These concepts are taught primarily using lectures with additional supporting material presented through the virtual learning environment (VLE) and are supported by a one-hour workshop session. Topic-specific workshop sessions are part of the core instructional methodology employed in the M.Pharm. course to reinforce lecture material. Students are divided into groups of approximately 25 and the session is repeated to accommodate the whole cohort. In a typical workshop session, students are provided with a worksheet detailing approximately six questions in an exam style format which they work through in the classroom. They are permitted to discuss questions amongst themselves and to access and use their notes or any technology to assist them. They may also direct questions or ask for assistance from one or two circulating instructors during the session who can provide individual guidance. These workshop sessions allow students to practice examples linked to the lecture material in a supported fashion. Once the whole cohort has completed the session, model answers are released through the VLE.

An integrated workshop was developed in order to assist students in visualising molecular structures. This workshop involved combining class worksheets and supporting material delivered via the VLE with the three dimensional structures described in the exercises presented in stand-alone virtual reality headsets. Supporting material, including model answers and short video clips covering each question were also released after the session. It was envisaged that the use of technology in a blended fashion would enhance engagement with the learning material and accommodate user preferences for different pedagogic approaches.

\section{Development of teaching materials}

The overall format of the workshop remained unaltered for this session. The sessions were delivered in normal classrooms with no changes made to room layout or class size (around 25 students). Six iterations of this workshop were run over three days (165 students in total). In each session, students were provided with a worksheet containing six examination-style questions covering molecular shape and structure, supporting material delivered via the VLE and access to stand-alone VR headsets preloaded with molecular structures. As with other M.Pharm. workshops, students were permitted to discuss the questions, ask for assistance from the two instructors and refer to their own notes or online material. Headsets used for this session were the Oculus Go. This headset is stand-alone and requires no external hardware. It has either $32 \mathrm{~GB}$ or $64 \mathrm{~GB}$ of storage, meaning that users do not require an internet connection to be able to use them as content can be loaded directly into the head mounted display. This type of headset allows users to view content freely but does not allow them to move around the virtual environment. 
Three molecular structures produced using ChemDraw Professional 16 (PerkinElmer Informatics) for the worksheet were imported into Chem3D (PerkinElmer Informatics). From here, they were saved as protein databank files (.pdb format) and imported into UCSF ChimeraX (Goddard et al., 2018). A script was written, using the instructions on the UCSF ChimeraX website (UCSF ChimeraX, 2020) and the resulting images were compiled into a $3 D$ video file. This file was then imported into Adobe Premier Pro (Adobe Inc.) where the 2D elements and visual and audio annotations were added. This file was then exported into a format suitable for the Oculus Go headsets and uploaded directly to the headsets to enable them to be viewed locally. An example is shown in Figure $\mathrm{C}$.

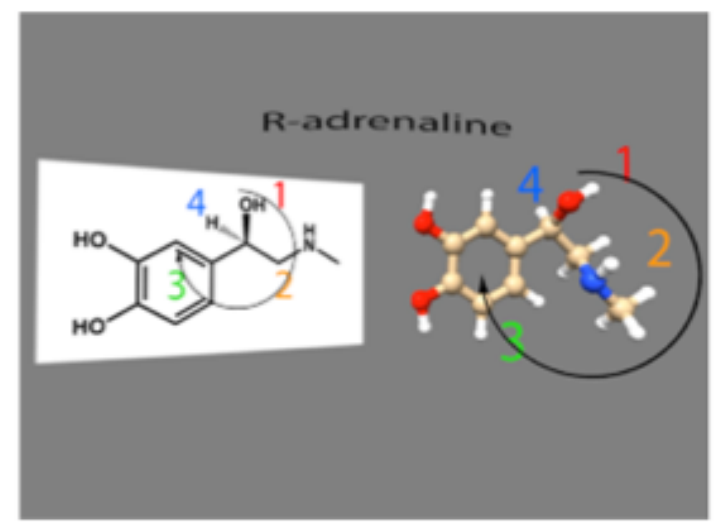

Figure C: A screenshot of one of the animations showing the assignment of chirality for a molecule of adrenaline. The molecule is presented in both 2D (left) and 3D (right) so both views can be seen simultaneously by the viewer.

A total of 21 Oculus Go headsets were used for the session which was carried out in a small class teaching space with no adaptations made to room layout (Figure D). At the start of the workshop, students were provided with the worksheet and instructed to follow normal workshop protocols. At the halfway point, a brief introduction to using the Oculus Go headsets was given which covered basic operating instructions and health and safety considerations. Students were informed they could use the headsets if they wished to explore the structures of the molecules which formed the basis of three of the six workshop questions. The aim of structuring the workshop in this fashion was to use VR technology to support the teaching of $3 \mathrm{D}$ structure in a standard workshop session (rather than the students regarding the session as a computing workshop).

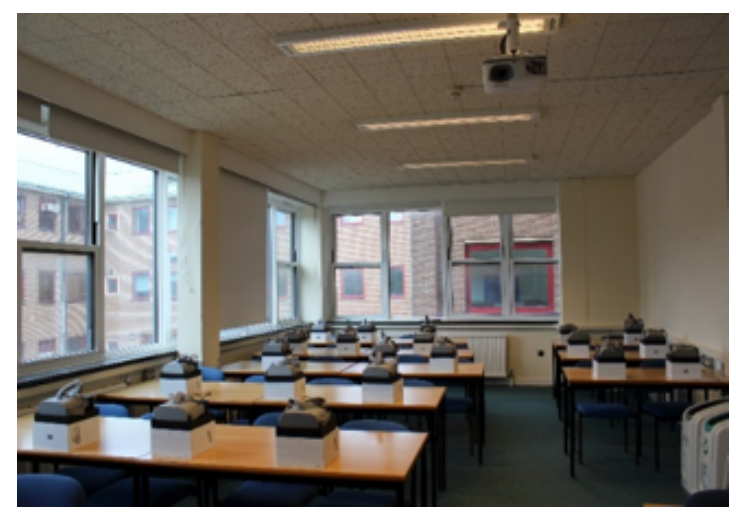

Figure 4: Room setup showing Oculus Go headsets enabling the viewing of molecular structures in the session

\section{Evaluation}

As part of the session evaluation, students $(n=74)$ from the final three iterations of this workshop were invited to provide informal feedback and suggestions for improvements at the end of the workshop session. They provided open response comments in an anonymous manner and on a voluntary basis. A 'ballot-box' system was used to collect comments. Comments from all three sessions were combined. A total of 151 individual comments were recorded from 74 students (a result of students submitting multiple comments and suggestions). Responses were grouped as positive, negative, providing suggestions or unrelated to the workshop. Themes relating to the structure of the session, the feel and atmosphere of the session and suggestions for improvement were identified.

Of the 151 responses received from 74 students, 108 were related to the session, 35 comments suggested possible improvements to future sessions, whereas eight did not relate to the session. In the latter case, these comments were predominantly related to wishing to use the VR headsets in a recreational setting. Of the 108 comments related to the session, 104 comments were positive and four were negative.

\section{Comments relating to the structure of the session}

Of the 104 positive comments received, 43 comments explicitly referenced the VR element of the session, whereas 61 comments were linked to the structure of the workshop as a whole. Comments regarding the structure of the workshop included those relating to the session being useful to reinforce concepts in the lectures and, the 
act of practicing questions within a supported environment assisting with examination preparation. Many of the comments also explicitly referenced that students had found the VR content useful in helping them visualise and understand molecular structure, for example, describing that 'the 3-D view of the molecule helps to really visualise the molecules', that 'VR help [sic] to understand the 3D nature of molecules' and 'really like the VR headset, really helpful to visualise the molecule'.

Four negative comments (from four different students) were received which related to the VR technology employed in the session. Of these negative comments, one was related to accessibility considerations precluding the use of head mounted displays. Two students commented that they did not find the VR technology useful, whereas one stated it was not enjoyable.

\section{Comments relating to the feel and atmosphere of the session}

Of 108 comments received which were focused on the session, 49 directly referenced the positive feel and atmosphere of the session. These included comments referencing the VR experience specifically and the overall feel of the workshop such as 'made the workshop fun and helped us see the molecules in 3D which helped with understanding' and 'using the headset was amazing!'. Numerous student comments were received relating to the class structure ensuring students could access individual help. Comments regarding the atmosphere of the class being relaxed were also noted, for example students commented that the relaxed atmosphere was also nice' and 'I loved the VR set and the relaxed nature of the workshop'.

\section{Comments relating to suggestions for improvements to the session}

35 comments were received suggesting improvements to the session. From these, 23 suggestions were related to logistical issues common to standard workshop sessions within the MPharm course. These included requests to increase the number of questions on the worksheet, include multiple choice questions and provide the model answers in the session.

Twelve comments were received which suggested technical improvements to the VR content and delivery. These included comments on audio quality such as 'I couldn't hear the audio too well at times, even at full volume' and the need for easier set-up.

\section{Future plans and recommendations}

In this programme description, the authors have described the design, deployment and evaluation of a blended workshop to support pharmacy undergraduate students to engage with concepts relating to the $3 \mathrm{D}$ structure of molecules. The workshop combined the use of traditional methods of delivering these sessions with molecular structures presented to the students using stand-alone virtual reality headsets.

Students feedback from the session highlighted that the majority of students found the combination of methods an effective approach to supporting their learning. It was also noted that comments were received relating to how headset use supported learning by allowing students to focus. Similarly, the use of virtual worlds as a teaching tool has been shown to reduce distraction and providing a space where students can concentrate (Winkelmann et al., 2020). It can be suggested that structuring sessions in this manner allows students and instructors to achieve balance between 'work-like' activities and 'play-like' activities. Participation in 'serious play' has been discussed extensively in the context of student engagement with particular reference to flow theory, where the ability to maintain control over a task is seen as a means to access higher order skills (Shernof et al., 2017; Shernoff et al., 2014).

What is particularly striking about this session is that numerous student comments were received relating to the positive atmosphere of the class. It has been suggested that students who are adjusting to new pedagogic environments (such as those experienced at the point of educational transitions) often struggle to adapt (Vermunt \& Donche, 2017). In the M.Pharm. course at Reading University, core chemical concepts (such as the ones covered in this session) are the first concepts incoming students experience at the beginning of their pharmacy course. Allowing learners some control over their learning environment by providing noncompulsory access to pedagogic strategies which are perceived as enjoyable may therefore contribute to the creation of an environment which will reduce self-doubt and anxiety resulting from material perceived as difficult being delivered at a point of transition.

\section{How a blended approach can overcome some of the challenges of deploying VR in the classroom.}

As described in the introduction, barriers for the adoption of virtual reality in the classroom include: cost of hardware, instructor confidence in working with new and unfamiliar technology, and health and safety considerations. 
In terms of cost, stand-alone VR headsets were used in this session. Stand-alone headsets are of significantly lower cost than high end interactive systems. Headsets of this type were chosen for classroom deployment as they represent a balance in terms of functionality, usability and cost. Sharing of headsets is (which also reduces the cost demand) facilitated by integrating technology into an existing workshop structure where the session is supported by (rather than reliant) on interaction with technology. It should be noted that the provision of VR technology does not require students to provide or bring their own technology to sessions, hence the cost burden is not transferred to the students.

In these sessions, standalone headsets were deployed in the classroom once the session had been preloaded. It is noted that this strategy is often employed when using TEL methods in a class setting, with instructors making use of commercial applications or, in the case of computational sessions, pre-existing software. As headsets can support the storage of multiple files they can be set up before the class which although requires some initial time investment, does not differ in demand from any other computational class once the content has been created and installed. In this instance, six sessions were run over the course of two days and the headsets required charging at the end of each day. In these sessions, a brief guide to operating the headsets was delivered verbally. Following analysis of student feedback linked to potential improvements, the authors have produced a 'quick-start' user guide for the headsets to accompany the future sessions. It is envisaged that this will not only support students in-class but will also support other instructors to deliver sessions incorporating VR technology.

It is important to note that the optional use of VR technology ensures that users are not reliant on the technology to deliver an output, hence there is less pressure on the instructor. Students were largely enthusiastic about the use of VR headsets, so were willing to experiment with and explore the technology (and guide others) rather than immediately request assistance.

In this instance stand-alone VR headsets with seated users were used in a normal classroom environment without any alterations necessary to the room layout. As the technology is portable and can be charged prior to the session, it can be moved between rooms with minimal set up and does not require access to power outlets in session. It is noted that this may be beneficial in terms of timetabling, as using such technology does not require access to specialist computer laboratories as a computational practical would - thus increasing the number of potential spaces which would be suitable for this type of activity.

Health and safety issues regarding the potential for trips and falls were not a consideration for this session as users remained seated whilst using the headsets. It should be noted that even VR with more interactive elements can often be used when seated which reduces the risk of falls. It is however still prudent to ensure adequate space between seated users to accommodate sudden movements. In this session, headsets were shared between students so students not engaging with the technology could also observe those interacting with the technology. Technology manufacturers also provide health and safety guidance which for most currently available headsets, including those used in this session) is available online. Students (and staff delivering the session) can therefore also be directed to this. Such guidance is easily embedded in the VLE as session pre-reading. In this session, one comment was noted regarding accessibility considerations preventing the use of the headsets. In order to address this, the VR content was provided as an alternative learning experience through the VLE, which also enabled all students to access the content outside of the session. We have also adapted the session introduction to reinforce that the headset use is optional.

It was also noted that in this session that suggesting students removed the straps from the headsets allowing the user to hold the device up (akin to using a pair of binoculars) allows the user to be fully in control of the experience. Showing students that they could hold the devices was also important to allow students wearing head coverings or having hair styles which would be affected by headset straps to engage with the device without feeling uncomfortable. Based on feedback from the session, the authors consider that students largely found the sessions enjoyable and were motivated to engage with a usually challenging topic. As such they demonstrate that VR technologies can be deployed in this context to enhance a blended learning experience and support students to engage with learning material. By combining different delivery methods (rather than make the technology the focus of the session) students could determine their own level of engagement with the virtual environment.

- Choose delivery systems which minimise strain on the instructor and the user

- Choose delivery systems which minimise the need for changes to the physical learning environment 


\section{Acknowledgements}

The authors gratefully acknowledge the Head of School Strategic Projects Scheme (School of Chemistry, Food and Pharmacy, University of Reading), Reading School of Pharmacy, University of Reading, The Friends of the University of Reading (reg. charity: 1173347) and RGSpaces (reg. charity: 1160023) for providing financial support enabling the purchase of hardware and software employed in this project. JPH and SAA would also like to thank the cohort for their feedback during the session and Somtochukwu Madueke for giving consent for his image to be used. Ethics representatives at the University deem this work to be an evaluation of a teaching innovation within the framework of the M.Pharm. programme and as such ethical permissions are not required. Adobe and Adobe Premier Pro are either registered trademarks or trademarks of Adobe in the United States and/or other countries.

\section{References}

Alfalah, S.F.M. (2018). Perceptions toward adopting virtual reality as a teaching aid in information technology. Education and Information Technologies, 23(6), 2633-2653. https://doi.org/10. $\underline{1007 / s 10639-018-9734-2}$

Alsharif, N.Z., Destache, C.J., \& Roche, V.F. (1999). Teaching medicinal chemistry to meet outcome objectives for pharmacy students. American Journal of Pharmaceutical Education, 63(1), 34-40.

Alsharif, N. Z., \& Qi, Y. (2014). A three-year study of the impact of instructor attitude, enthusiasm, and teaching style on student learning in a medicinal chemistry course. American Journal of Pharmaceutical Education, 78(7), 132. https://doi.org/10.5688/ ajpe787132

Amin, A., Gromala, D., Tong, X., \& Shaw, C. (2016). Immersion in cardboard VR compared to a traditional head-mounted display. Paper presented at the International Conference on Virtual, Augmented and Mixed Reality. https://doi.org/10.1007/9783-319-39907-2 25

Ang, K.C.S., \& van Reyk, D. (2013). 'Teach me chemistry like a ladder and make it real'-barriers and motivations students face in learning chemistry for bioscience. International Journal of Innovation in Science and Mathematics Education, 21(2), 1-12

Armbruster, P., Patel, M., Johnson, E., \& Weiss, M. (2009). Active learning and student-centered pedagogy improve student attitudes and performance in introductory biology. CBE life Sciences Education, 8(3), 203-213. https://doi.org/10.1187/cbe. $\underline{09-03-0025}$

Brown, A., \& Green, T. (2016). Virtual Reality: Low-Cost Tools and Resources for the Classroom. TechTrends, 60(5), 517-519. https:// doi.org/10.1007/s11528-016-0102-z

Brown, C.E., Henry, M.L.M., Barbera, J., \& Hyslop, R.M. (2012). A bridge between two cultures: Uncovering the chemistry concepts relevant to the nursing clinical practice. Journal of Chemical Education, 89(9), 1114-1121. https://doi.org/10.1021/ed200041x
Carvalho, I., Borges, Á.D.L., \& Bernardes, L.S.C. (2005). Medicinal chemistry and molecular modeling: An integration to teach drug structure-activity relationship and the molecular basis of drug action. Journal of Chemical Education, 82(4), 588-596. https://doi. org/10.1021/ed082p588

Chase, A., Pakhira, D., \& Stains, M. (2013). Implementing Process-Oriented, Guided-Inquiry Learning for the First Time: Adaptations and Short-Term Impacts on Students' Attitude and Performance. Journal of Chemical Education, 90(4), 409-416. https://doi.org/10.1021/ed300181t

Clifton, I., \& McKillup, S.C. (2016). Why such success?: Nursing students show consistently high satisfaction with bioscience courses at a regional university. Australian Journal of Advanced Nursing, 33(3), 21

Cooper, A.K., \& Oliver-Hoyo, M.T. (2017). Creating 3D physical models to probe student understanding of macromolecular structure. Biochemistry and Molecular Biology Education: a Bimonthly Publication of the International Union of Biochemistry and Molecular Biology, 45(6), 491-500. https://doi.org/ $\underline{10.1002 / \mathrm{bmb} .21076}$

Coyne, L., Takemoto, J.K., Parmentier, B.L., Merritt, T., \& Sharpton, R.A. (2018). Exploring virtual reality as a platform for distance team-based learning. Currents in Pharmacy Teaching and Learning, 10(10), 1384-1390. https://doi.org/10.1016/i.cptl. $\underline{2018.07 .005}$

Craft, J.A., Hudson, P.B., Plenderleith, M.B., \& Gordon, C.J. (2017). Registered nurses' reflections on bioscience courses during the undergraduate nursing programme: an exploratory study. Journal of Clinical Nursing, 26(11-12), 1669-1680. https://doi.org/10.1111/ jocn.13569

Davies, A.G., Crohn, N.J., \& Treadgold, L.A. (2019). Can virtual reality really be used within the lecture theatre? BMJ Simulation and Technology Enhanced Learning, 5(4), 234. https://doi.org/ $\underline{10.1136 / \text { bmjstel-2017-000295 }}$

Dries, D.R., Dean, D.M., Listenberger, L.L., Novak, W.R., Franzen, M.A., \& Craig, P.A. (2017). An expanded framework for biomolecular visualization in the classroom: Learning goals and competencies. Biochem Mol Biol Educ, 45(1), 69-75. https://doi. org/10.1002/bmb.20991

Faruk Khan, M.O., Deimling, M.J., \& Philip, A. (2011). Medicinal chemistry and the pharmacy curriculum. American Journal of Pharmaceutical Education, 75(8). https://doi.org/10.5688/ajpe758161

Fergus, S., \& Kostrzewski, A. (2011). Why the contextualisation of chemistry in the MPharm curriculum is needed. Pharmaceutical Journal, 286(7650-7651), 513-514

Flavián, C., Ibáñez-Sánchez, S., \& Orús, C. (2019). The impact of virtual, augmented and mixed reality technologies on the customer experience. Journal of Business Research, 100, 547-560. https://doi.org/10.1016/i.jbusres.2018.10.050

Freeman, S., Eddy, S. L., McDonough, M., Smith, M.K., Okoroafor, N., Jordt, H., \& Wenderoth, M.P. (2014). Active learning increases student performance in science, engineering, and mathematics. Proc Natl Acad Sci USA, 111(23), 8410-8415. https://doi.org/ $\underline{10.1073 / \text { pnas.1319030111 }}$

Friedel, J.M., \& Treagust, D.F. (2005). Learning bioscience in nursing education: perceptions of the intended and the prescribed curriculum. Learning in Health and Social Care, 4(4), 203-216. https://doi.org/10.1111/i.1473-6861.2005.00104.x 
Galactig. (2019). Dementia First Hand (Yn Fy Nwylol). Available at: https://galactig.com/portfolio/dementia-first-hand/

Garcia-Palacios, A., Hoffman, H., Carlin, A., Furness lii, T., \& Botella, C. (2002). Virtual reality in the treatment of spider phobia: a controlled study. Behaviour Research and Therapy, 40(9), 983-993. https://doi.org/10.1016/S0005-7967(01)00068-7

General Pharmaceutical Council. (2011). Future pharmacists: Standards for the initial education and training of pharmacists. Available at; https://www.pharmacyregulation.org/sites/default/ files/document/future pharmacists standards for the initial ed ucation and training of pharmacists.pdf

Gibbons, R.E., Xu, X., Villafañe, S.M., \& Raker, J.R. (2018). Testing a reciprocal causation model between anxiety, enjoyment and academic performance in postsecondary organic chemistry. Educational Psychology, 38(6), 838-856. https://doi.org/10.1080/ $\underline{01443410.2018 .1447649}$

Gloudeman, M.W., Shah-Manek, B., Wong, T.H., Vo, C., \& Ip, E.J. (2018). Use of condensed videos in a flipped classroom for pharmaceutical calculations: Student perceptions and academic performance. Current in Pharmacy Teaching and Learning, 10(2), 206-210. https://doi.org/10.1016/i.cptl.2017.10.001

Goddard, T.D., Huang, C.C., Meng, E.C., Pettersen, E.F., Couch, G.S., Morris, J.H., \& Ferrin, T.E. (2018). UCSF ChimeraX: Meeting modern challenges in visualization and analysis. Protein Sci, 27(1), 14-25. https://doi.org/10.1002/pro.3235

Gordon, C.J., \& Hughes, V.K. (2013). Creating relevance and credibility: New approaches for bioscience education in pre-registration nursing curriculum. International Journal of Innovation in Science and Mathematics Education, 21(2), 53-65

Hall, S., Grant, G., Arora, D., Karaksha, A., McFarland, A., Lohning, A., \& Anoopkumar-Dukie, S. (2017). A pilot study assessing the value of $3 \mathrm{D}$ printed molecular modelling tools for pharmacy student education. Currents in Pharmacy Teaching and Learning, 9(4), 723-728. https://doi.org/10.1016/i.cptl.2017.03.029

Hedberg, J., \& Alexander, S. (1994). Virtual Reality in Education: Defining Researchable Issues. Educational Media International, 31(4), 214-220. https://doi.org/10.1080/0952398940310402

Johnson, T., Bauler, L., Vos, D., Hifko, A., Garg, P., Ahmed, M., \& Raphelson, M. (2020). Virtual Reality Use for Symptom Management in Palliative Care: A Pilot Study to Assess User Perceptions. Journal of Palliative Medicine. https://doi.org/10. 1089/ipm.2019.0411

Keefe, F.J., Huling, D.A., Coggins, M.J., Keefe, D.F., Rosenthal, M.Z., Herr, N.R., \& Hoffman, H.G. (2012). Virtual reality for persistent pain: a new direction for behavioral pain management. Pain, 153(11), 2163. https://doi.org/10.1016/j.pain.2012.05.030

Latta, J.N., \& Oberg, D.J. (1994). A conceptual virtual reality model. IEEE Computer Graphics and Applications, 14(1), 23-29. https:// doi.org/10.1109/38.250915

Lewis, T., Aggarwal, R., Rajaretnam, N., Grantcharov, T., \& Darzi, A. (2011). Training in surgical oncology-The role of VR simulation. Surgical Oncology, 20(3), 134-139. https://doi.org/10.1016/ j.suronc.2011.04.005

Limniou, M., Roberts, D., \& Papadopoulos, N. (2008). Full immersive virtual environment CAVETM in chemistry education. Computers and Education, 51(2), 584-593. https://doi.org/10. 1016/j.compedu.2007.06.014
Logishetty, K., Rudran, B., \& Cobb, J.P. (2019). Virtual reality training improves trainee performance in total hip arthroplasty: a randomized controlled trial. Bone Joint J, 101-b(12), 1585-1592. https://doi.org/10.1302/0301-620X.101B12.BJJ-2019-0643.R1

Mahaffey, A.L. (2019a). A Complementary Laboratory Exercise: Introducing Molecular Structure-Function Topics to Undergraduate Nursing Health Professions Students. Journal of Chemical Education, 96(10), 2188-2193. https://doi.org/10.1021/ acs.jchemed.9b00388

Mahaffey, A.L. (2019b). It's All Relative! Engaging Nursing and Exercise Science Students in Chemical Education Using Medical Case Studies. Journal of Chemical Education, 96(10), 2253-2260. https://doi.org/10.1021/acs.jchemed.9b00329

Oculus. (2019). Oculus Go Health \& Safety. Available at: https://www.oculus.com/safety-center/go/?locale=en_GB

Özer, Ö., \& Yöntem, M. K. (2019). A technological tool for treating social anxiety: Virtual reality. Anxiety, 3(36), 37-41. https://doi.org/10.14744/phd.2019.75010

Papachristos, N.M., Vrellis, I., \& Mikropoulos, T.A. (2017, 3-7 July 2017). A Comparison between Oculus Rift and a Low-Cost Smartphone VR Headset: Immersive User Experience and Learning. Paper presented at the 2017 IEEE 17th International Conference on Advanced Learning Technologies (ICALT). https://doi.org/10.1109/ICALT.2017.145

Prescott, J., Wilson, S.E., \& Wan, K.-W. (2014). Pharmacy students' perceptions of natural science and mathematics subjects. American Journal of Pharmaceutical Education, 78(6), 118. https://doi.org/10.5688/ajpe786118

Prince, M. (2004). Does Active Learning Work? A Review of the Research. Journal of Engineering Education, 93(3), 223-231. https://doi.org/10.1002/i.2168-9830.2004.tb00809.x

Ralph, N., Birks, M., Cant, R., Chun Tie, Y., \& Hillman, E. (2017). How should science be taught to nurses? Preferences of registered nurses and science teaching academics. Collegian, 24(6), 585-591. https://doi.org/10.1016/j.colegn.2017.01.004

Rebenitsch, L., \& Owen, C. (2016). Review on cybersickness in applications and visual displays. Virtual Reality, 20(2), 101-125. https://doi.org/10.1007/s10055-016-0285-9

Rose, T. M. (2018). Lessons Learned Using a Demonstration in a Large Classroom of Pharmacy Students. American Journal of Pharmaceutical Education, 82(9), 6413-6413. https://doi.org/10. $\underline{5688 / a j p e 6413}$

Shadle, S.E., Marker, A., \& Earl, B. (2017). Faculty drivers and barriers: laying the groundwork for undergraduate STEM education reform in academic departments. International Journal of STEM Education, 4(1), 8. https://doi.org/10.1186/s40594$\underline{017-0062-7}$

Sharecare. (2017). YOU by Sharecare. Available at: http://www.sharecare.com/pages/vr

Sharples, S., Cobb, S., Moody, A., \& Wilson, J.R. (2008). Virtual reality induced symptoms and effects (VRISE): Comparison of head mounted display (HMD), desktop and projection display systems. Displays, 29(2), 58-69. https://doi.org/10.1016/i.displa.2007.09.005 
Shernof, D.J., Ruzek, E.A., Sannella, A.J., Schorr, R.Y., Sanchez-Wall, L., \& Bressler, D.M. (2017). Student Engagement as a General Factor of Classroom Experience: Associations with Student Practices and Educational Outcomes in a University Gateway Course. Frontiers in Psychology, 8(994). https://doi.org/10.3389/ fpsyg.2017.00994

Shernoff, D.J., Csikszentmihalyi, M., Schneider, B., \& Shernoff, E.S. (2014). Student engagement in high school classrooms from the perspective of flow theory. In Applications of flow in human development and education. Springer. pp. 475-494. https://doi. org/10.1007/978-94-017-9094-9 24

Smith, A.L., Paddock, J.R., Vaughan, J.M., \& Parkin, D.W. (2018). Promoting Nursing Students' Chemistry Success in a Collegiate Active Learning Environment: "if i Have Hope, i Will Try Harder". Journal of Chemical Education, 95(11), 1929-1938. https://doi.org/10.1021/acs.jchemed.8b00201

Smith, P.C., \& Hamilton, B.K. (2015). The effects of virtual reality simulation as a teaching strategy for skills preparation in nursing students. Clinical Simulation in Nursing, 11(1), 52-58. https://doi.org/10.1016/i.ecns.2014.10.001

Stewart, D.W., Brown, S.D., Clavier, C.W., \& Wyatt, J. (2011). Active-learning processes used in US pharmacy education. American Journal of Pharmaceutical Education, 75(4), 68. https://doi.org/10.5688/ajpe75468

Trippier, P.C. (2018). Molecule of the Month: Relating Organic Chemistry Principles to Drug Action. Journal of Chemical Education, 95(7), 1112-1117. https://doi.org/10.1021/acs.jchemed $.8 \mathrm{~b} 00120$

UCSF ChimeraX. (2020). UCSF ChimeraX User Guide. Available at: http://www.cgl.ucsf.edu/chimerax/docs/user/index.html

Vahdat, L. (2009). Integrating students' learning with professional practice through laboratory and workshop based teaching in undergraduate medicinal chemistry. Pharmacy Education, 9

Vermunt, J.D., \& Donche, V. (2017). A Learning Patterns Perspective on Student Learning in Higher Education: State of the Art and Moving Forward. Educational Psychology Review, 29(2), 269-299. https://doi.org/10.1007/s10648-017-9414-6

Wehle, S., \& Decker, M. (2016). Perception of the Relevance of Organic Chemistry in a German Pharmacy Students' Course. American Journal of Pharmaceutical Education, 80(3), 40. https://doi.org/10.5688/ajpe80340

Widanski, B.B., \& McCarthy, W.C. (2009). Assessment of Chemistry Anxiety in a Two-Year College. Journal of Chemical Education, 86(12), 1447. https://doi.org/10.1021/ed086p1447

Winkelmann, K., Keeney-Kennicutt, W., Fowler, D., Lazo Macik, M., Perez Guarda, P., \& Ahlborn, C.J. (2020). Learning gains and attitudes of students performing chemistry experiments in an immersive virtual world. Interactive Learning Environments, 1-15. https://doi.org/10.1080/10494820.2019.1696844 